\title{
THE CHEMICAL BACKGROUND OF INTERVERTEBRAL DISC PROLAPSE
}

\author{
P. E. G. Mitchell, N. G. C. Hendry and W. Z. Billewicz, ${ }^{*}$ Aberdeen, Scotland
}

This paper has as its principal object the demonstration of changes in the chemical composition of the nucleus pulposus associated with disc prolapse. In pursuance of this it has been necessary also to investigate along parallel lines the chemistry of the normal ageing process.

In the past few years a great deal has been learned about the normal intervertebral disc, and about the changes in it which accompany advancing age. Much light has been thrown on the functioning of the disc by Sylvén's work (1951) which established the ultrastructure of the nucleus pulposus: he showed it to consist of a network of fine collagen fibrils, about which are aggregated clumps of a polysaccharide/protein complex forming a gel and responsible for the very high imbibition capacity of the nucleus. The exact nature of the polysaccharide. which has been the subject of some disagreement, is now in less doubt. Earlier identifications of hyaluronic acid are open to question; but the presence of chondroitin sulphates $\mathrm{A}$ and $\mathrm{C}$. and of a keratosulphate (Hall, Floyd, Happey, Horton and Naylor 1957) has been confirmed by other workers, including Davidson and Woodhall (1959), who have shown a change in the ratio of these two polysaccharides in prolapse and "degeneration." Exact identification of the polysaccharide was not relevant to the present work, but would have been of additional interest in the light of Davidson and Woodhall's findings.

It is known that normal ageing is accompanied by a gradual increase in collagen and a decrease in mucoprotein, the morphology of this process having been closely studied. This work has been summarised by Birkett (1950) and by Naylor, Happey and Macrae (1954). In deranged discs a lowering of imbibition pressure has been found, and it has been suggested that this could set up mechanical and hydrostatic effects sufficiently severe to rupture the annulus. Also, as imbibition is a function of gels, it has been postulated that a quantitative or qualitative change in nuclear mucoprotein is the immediate cause of disc derangement (Hendry 1958a, 1958b). Other workers have had similar views on the existence of mucoprotein derangement, but have assumed some hyperhydration phenomenon to be necessary to explain annular rupture (Naylor and Smare 1953; Charnley 1952; Bush, Horton, Smare and Naylor 1956; Smare, Happey and Naylor 1958). There has been some confusion on this subject, some of it arising from the paucity of published work comparing normal and prolapsed discs, and some from the false premise that the breakdown of a gel will result in an increase in hydrophilia, in the same way as does molecular breakdown in an osmotic system. Further, the observation of reduced water-binding capacity in the prolapsing nucleus has in the past been mistakenly equated with the desiccation of ageing. More recently, however, the possibility that these might be two separate processes has been recognised (Lancet annotation 1959).

In the present work forty-four normal discs from cadavers have been compared with disc material from fifty-six patients in whom a protrusion or extrusion had been found at operation. The method of collection was as previously described (Hendry 1958a). Values were obtained in each specimen for collagen, polysaccharide and total protein, the collagen being estimated as hydroxyproline, the polysaccharide as hexosamine and reducing sugars, and the total protein as nitrogen. The two groups were matched for age (Table I) and, in the clinical group, the length of the patient's history was also noted-in particular the time between the first onset of relevant symptoms and laminectomy. Difficulty arises in directly comparing

\footnotetext{
* Co-author responsible for statistical appendix.
}

VOL. 43 B, NO. I, FEBRUARY 1961 
TABLE I

Discs Obtained at Necropsy and at Operation = Values per 100 Milligrams Dry Weight for Hexosamine, Reducing Sugars, Collagen and Total Protein (as Nitrogen). Relation to Age in Decades

\begin{tabular}{|c|c|c|c|c|c|}
\hline \multirow{2}{*}{\multicolumn{2}{|c|}{$\underset{\text { (years) }}{\text { Age }}$}} & \multicolumn{2}{|c|}{ Number of dises } & \multicolumn{2}{|c|}{ Hexosamine } \\
\hline & & Necropsy & Operation & Necropsy & Operation \\
\hline Under 20 & . & 5 & 6 & $6 \cdot 44$ & $5 \cdot 70$ \\
\hline $20-29$ & . & 5 & 7 & $7 \cdot 15$ & 3.99 \\
\hline $30-39$ & . & 7 & 9 & $9 \cdot 00$ & $4 \cdot 03$ \\
\hline $40-49$ & . & 14 & 18 & $7 \cdot 51$ & $4 \cdot 18$ \\
\hline $50-59$ & . & 13 & 16 & $5 \cdot 51$ & 3.94 \\
\hline Total & . & 44 & 56 & & \\
\hline Mean & . & & & 6.99 & $4 \cdot 23$ \\
\hline Standard & tion & & & $2 \cdot 13$ & $2 \cdot 22$ \\
\hline
\end{tabular}

the two groups because of the presence in one of them of this additional factor of the duration of the disability. In order that there should be no confusion between this and the effects due to the patient's age, all data were subjected to a full statistical analysis, which is published as an appendix. Certain facts about the two groups are, however, immediately apparent, and are indicated below under " Results and Comments." Comparison of the two groups and the deductions that can be made therefrom then follow under "Discussion."

\section{METHODS}

Preparation-The disc material was chopped finely, ground in acetone and solid carbon dioxide, and the resulting material filtered and dried in vacuo. This dry material was again ground until a homogenous powder was obtained.

Analytical methods-Aliquots of the powder were then analysed.

Estimation of hexosamine - The method employed was that of Elson and Morgan (1933) as modified by Consden (1958). In principle, this involves hydrolysis of the polysaccharides; the hexosamines are extracted with acetyl acetone in alkaline solution and converted to a pyrrole derivative. This gives a coloured condensation product with p-dimethylaminobenzaldehyde. The colour is then measured. Standards are carried through the procedure.

Estimation of reducing sugar-After hydrolysis of the disc, estimations were made by the method of Nelson (1944) using a Somogyi Copper reagent.

Estimation of collagen-The method used was that of Neumann and Logan (1950), as modified by Martin and Axelrod (1953). This involves the conversion of collagen to soluble gelatin, which is then hydrolysed. The resultant hydroxyproline is then estimated following oxidation and incubation with p-dimethylaminobenzaldehyde. Standards of hydroxyproline are again used. The collagen is then calculated by the use of the appropriate conversion factor.

Estimation of nitrogen-The Kjeldahl method, employing a Markham and Smith microdistillation apparatus, was used. Digestion was carried out in sulphuric acid with selenium dioxide as catalyst.

\section{RESULTS AND COMMENTS}

Normal necropsy discs-Specimens were taken from subjects who had died without known vertebral disease. In the absence of any known chemical or other criterion of normality, discs were accepted for this group provided simply they showed no bulging or attenuation of 
TABLE I-continued

Discs Obtained at Necropsy and at Operation = Values per 100 Milligrams Dry Weight for Hexosamine, Reducing Sugars, Collagen and Total Protein (as Nitrogen). Relation to age in Decades

\begin{tabular}{|c|c|c|c|c|c|}
\hline \multicolumn{2}{|c|}{ Reducing sugars } & \multicolumn{2}{|c|}{ Collagen } & \multicolumn{2}{|c|}{ Total protein } \\
\hline $\begin{array}{l}\text { Necropsy } \\
\text { specimens }\end{array}$ & $\begin{array}{l}\text { Operation } \\
\text { specimens }\end{array}$ & $\begin{array}{l}\text { Necropsy } \\
\text { specimens }\end{array}$ & $\begin{array}{l}\text { Operation } \\
\text { specimens }\end{array}$ & $\begin{array}{c}\text { Necropsy } \\
\text { specimens }\end{array}$ & $\begin{array}{l}\text { Operation } \\
\text { specimens }\end{array}$ \\
\hline 8.40 & $6 \cdot 58$ & $18 \cdot 66$ & 38.62 & 8.06 & $10 \cdot 93$ \\
\hline $10 \cdot 43$ & $7 \cdot 27$ & 24.90 & $46 \cdot 74$ & 8.48 & $11 \cdot 28$ \\
\hline $12 \cdot 14$ & $6 \cdot 51$ & $28 \cdot 96$ & $36 \cdot 75$ & $8 \cdot 44$ & $11 \cdot 39$ \\
\hline $11 \cdot 85$ & $6 \cdot 58$ & $23 \cdot 90$ & $41 \cdot 77$ & $8 \cdot 72$ & $12 \cdot 25$ \\
\hline $11 \cdot 20$ & $5 \cdot 88$ & $26 \cdot 13$ & $50 \cdot 54$ & 8.61 & 11.43 \\
\hline $11 \cdot 15$ & 6.45 & $24 \cdot 88$ & 43.75 & 8.54 & $11 \cdot 62$ \\
\hline 4.68 & 3.78 & $5 \cdot 18$ & $14 \cdot 60$ & $1 \cdot 32$ & $1 \cdot 33$ \\
\hline
\end{tabular}

the annulus or any Schmorl's nodes. It is possible that some specimens were in fact in a "pre-protrusion " phase, but any discrepancy arising from this does not appear to be significant. This difficulty should in future be easily avoidable in the light of the figures given below.

The mean values per 100 milligrams dry weight were, for hexosamine 6.99 milligrams, for reducing sugars 11.15 milligrams, for collagen 24.88 milligrams, and for nitrogen 8.54 milligrams (Table I). When the discs are grouped according to the age of the subject (Figs. 1 to 5) three facts emerge-1) the polysaccharide content is considerably influenced by age, 2) there is a gradual increase in collagen content as age advances, 3) the nitrogen level remains virtually constant. This last finding is of considerable importance because of the light it throws on the metabolic process involved in normal ageing, and also on the relation between this and prolapse. It is discussed fully below. The increase in collagen confirms the deductions which can be made from morphological studies already reported.

No reason can be adduced for the increase in hexosamine-yielding polysaccharide up to the fourth decade, and its gradual decline thereafter, nor for the slight progressive increase in the yield of reducing sugars. It is of very considerable interest to note that the identical sequence of changes has been reported by Hass (1943) in the hexosamine content of costal cartilage.

Prolapsed discs-A striking departure from normal was found in all four estimations (Table I and Figs. 6 to 9). The mean values per 100 milligrams dry weight were as follows, the normal figures being shown in brackets after each:- hexosamine 4.23 milligrams (6.99), collagen 43.75 milligrams (24.88), reducing sugars 6.45 milligrams (11.15), nitrogen 11.62 milligrams (8.54).

Grouping of these discs by age suggests that a clear relationship between age and the chemical contents no longer exists (Table I). There is quite striking uniformity in the hexosamine and in the reducing sugar levels in all age groups, suggesting that, irrespective of the normal for that age, the polysaccharide content must fall to a certain critical level before prolapse occurs. The changes in collagen content, when related to age, are not statistically significant, nor are those in total protein. Two abnormalities of the prolapsed disc are therefore immediately apparent-first, that the amounts of all the principal constituents are significantly altered, hexosamine and reducing sugars being decreased and collagen and total protein increased; and second, that the changes normally related to age no longer occur.

In contrast with the second finding, the relationship between changes in the chemical composition and the duration of the patients' disability is clear and progressive (Fig. 10).

VOL. 43 B, No. 1, FEBRUARY 1961 


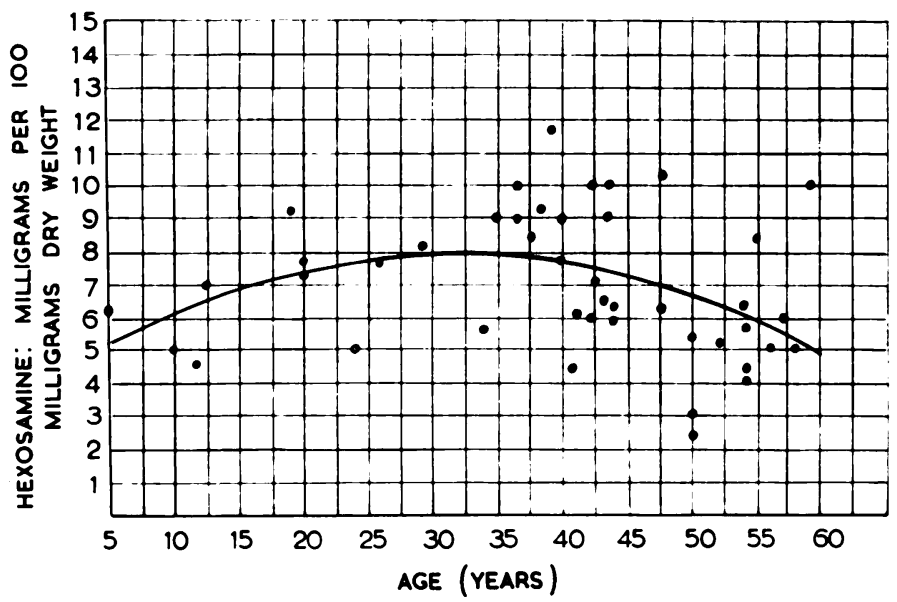

FiG. 1

Diagram showing scatter of values obtained for hexosamine in forty-four discs removed at necropsy, with fitted regression line. Hexosamine $=4.115$ +.23882 age -.00374 age 2 .

Fig. 2

Diagram showing scatter of values obtained for reducing sugars in fortyfour discs removed at necropsy, with fitted regression line. Reducing sugars $=7.711+\cdot 08687$ age
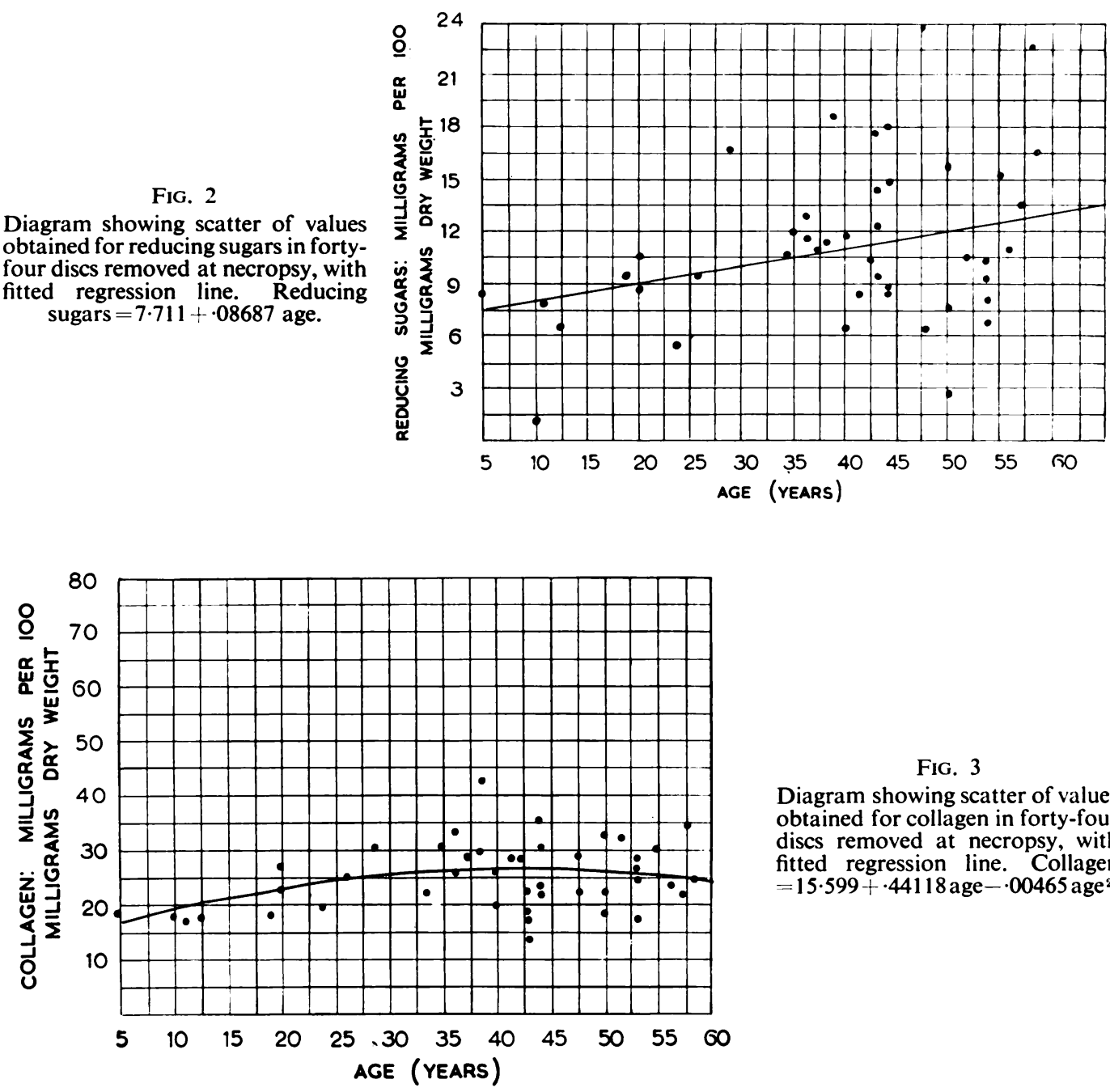

FIG. 3

Diagram showing scatter of values obtained for collagen in forty-four discs removed at necropsy, with fitted regression line. Collagen $=15.599+.44118 \mathrm{age}-.00465 \mathrm{age}^{2}$. 


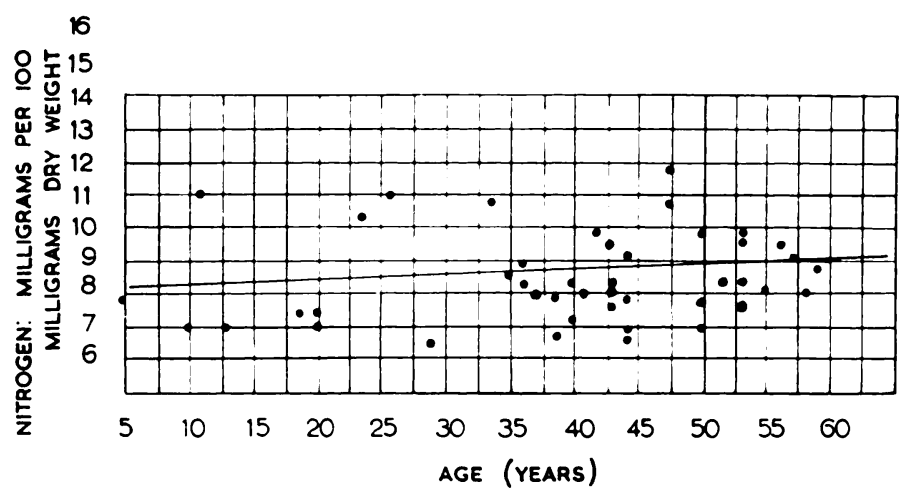

FiG. 4

Diagram showing scatter of values obtained for nitrogen in forty-four discs removed at necropsy, with fitted regression line. Nitrogen 7.991: 01391 age.

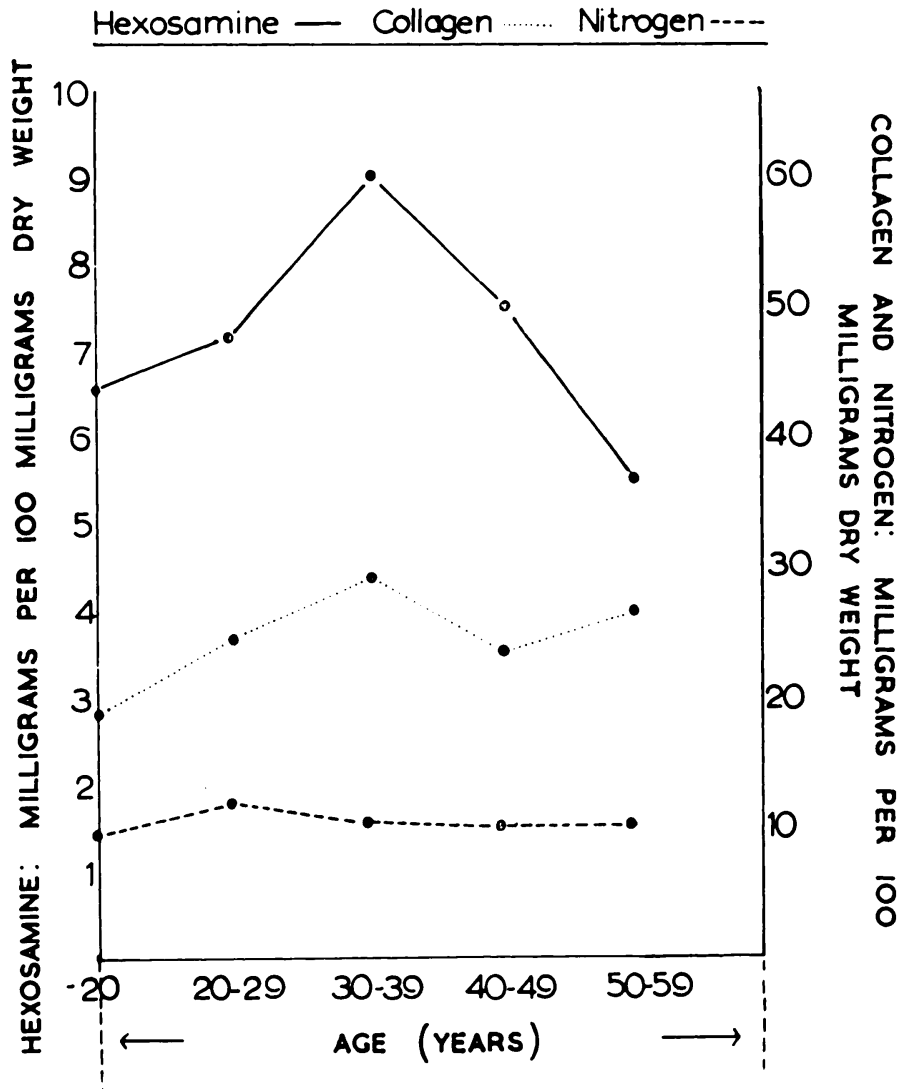

Fig. 5

Mean values for hexosamine, collagen and total protein (as nitrogen) in normal discs, showing changes associated with ageing. Note the peak reached by the hexosamine content in the thirty to thirty-nine age group, and the gradual increase in collagen content with advancing age. 
Hexosamine falls sharply as the disability continues, collagen rises, and total nitrogen once again remains constant, although at a higher level than normal. Any suspicion that the loss in polysaccharide is merely the result of autolysis, secondary to the mechanical derangement, is countered by the constancy of the nitrogen level and by the rising collagen content, both of which must indicate that an active metabolic process still continues. This process appears

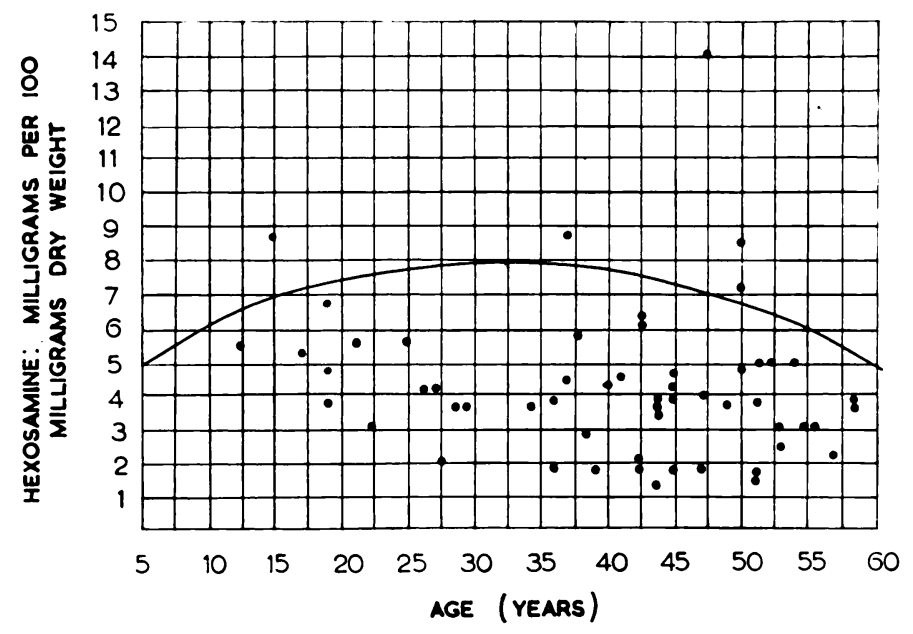

Fig. 6

Diagram showing scatter of values obtained for hexosamine in fifty-six prolapsed discs removed at operation. The regression line for normal discs is shown. Note the marked reduction of hexosamine.

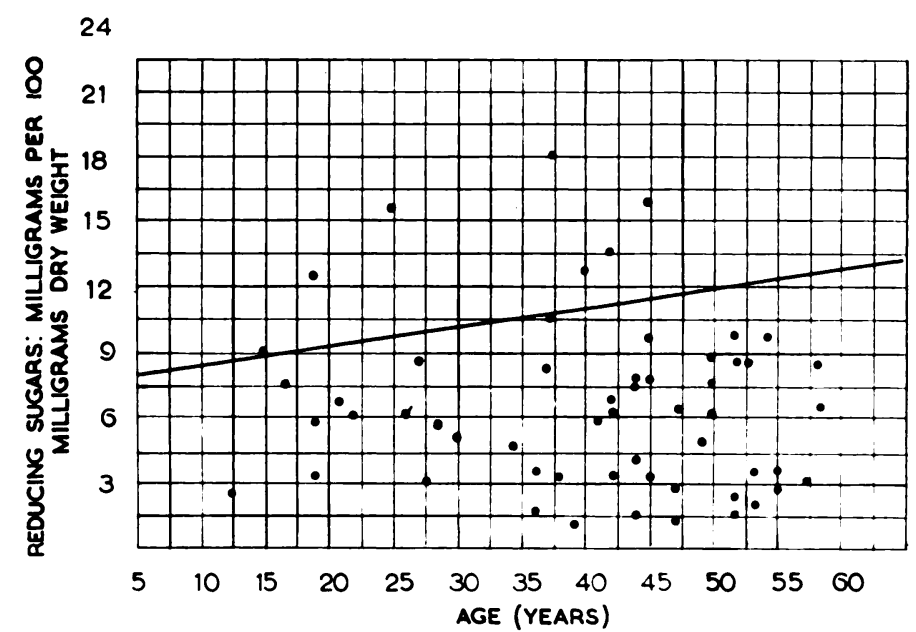

Fig. 7

Diagram showing scatter of values obtained for reducing sugars in fifty-six prolapsed discs removed at operation. The regression line for normal discs is shown. Note the marked reduction of reducing sugars.

from the figures to be a specific one, characteristic of the prolapsed disc, independent of the patient's age, and advancing according to the duration of the disability.

\section{DISCUSSION}

As no age-dependent changes have been found in the prolapsing disc, it is impossible to write in terms of a process of " pathological ageing" which might be contrasted directly with " normal ageing." Rather must one think of a physiological sequence (Fig. 5) from any point 
of which a pathological train of events may begin, leading first to prolapse and then to an end-state in which there is much less polysaccharide and much more collagen than in the most aged of normal discs (Fig. 10). Other pathological states such as osteoarthritis no doubt also have characteristic chemical changes, and the dividing lines between them may well be indefinite. It seems likely that the relative rate of change in the two main constituents of the

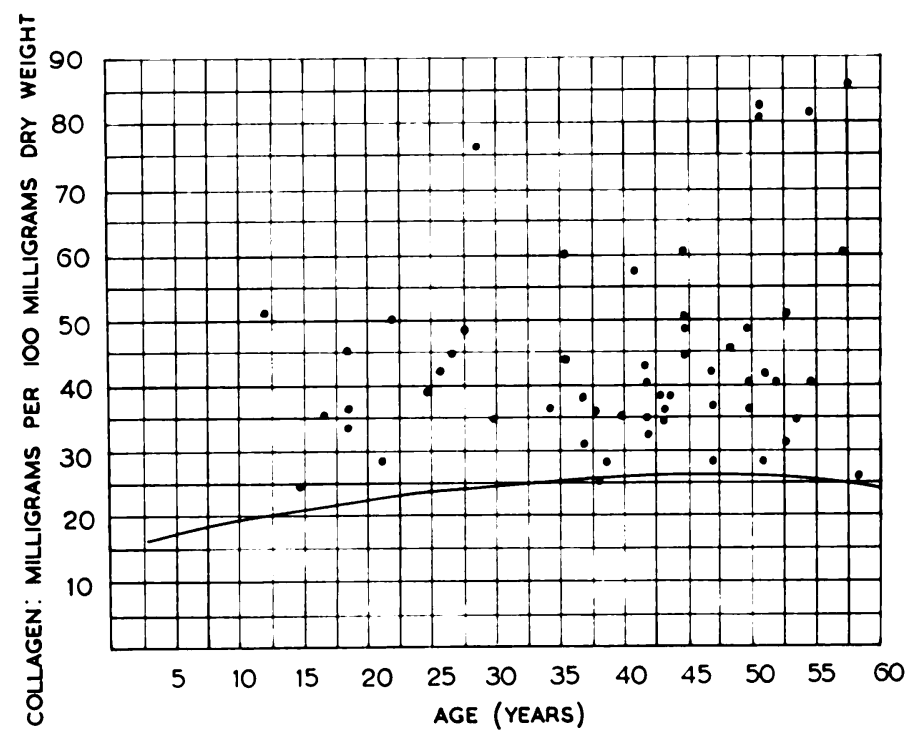

FIG. 8

Diagram showing scatter of values obtained for collagen in fifty-six prolapsed discs removed at operation. The regression line for normal discs is shown. Note the increase in collagen.

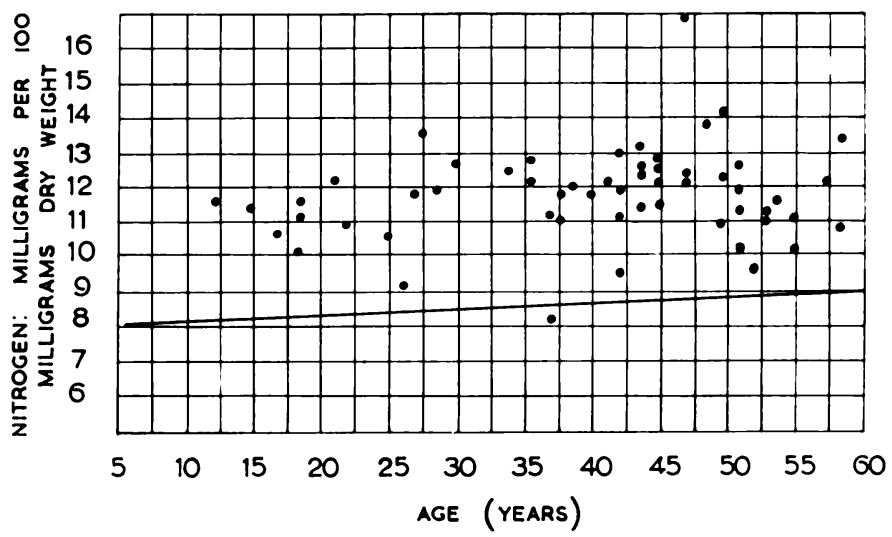

FiG. 9

Diagram showing the scatter of values obtained for nitrogen in fifty-six prolapsed discs removed at operation. The regression line for normal discs is shown. Note the increase of total protein (as nitrogen).

nucleus is important in determining what mechanical effects may follow. The presence at any one time of a relatively large amount of actively breaking-down polysaccharide, with the consequent setting up of hydrostatic effects, is probably the crucial factor in the " prolapsing" sequence.

From an etiological point of view it is interesting to consider at what point in the patient's life the processes of normal ageing and pathological polysaccharide loss diverge. It could be

VOL. $43 \mathrm{~B}$, NO. 1, FEBRUARY 1961

$\mathrm{K}$ 
argued that " derangeability" arose from a failure of the normal polysaccharide increase to appear in the third and fourth decades. This would, however, imply that for patients in the age group where prolapse is commonest an abnormality had been present without causing symptoms for perhaps as long as ten or fifteen years, and this is unlikely. It seems more probable that the pathological process supervenes for reasons unknown at any time and that the maximum change in physical characteristics of the discs, and therefore the highest clinical incidence, occurs when the mucoprotein content should normally be at its highest, namely in the fourth decade. From the deductions made below concerning the metabolism of both

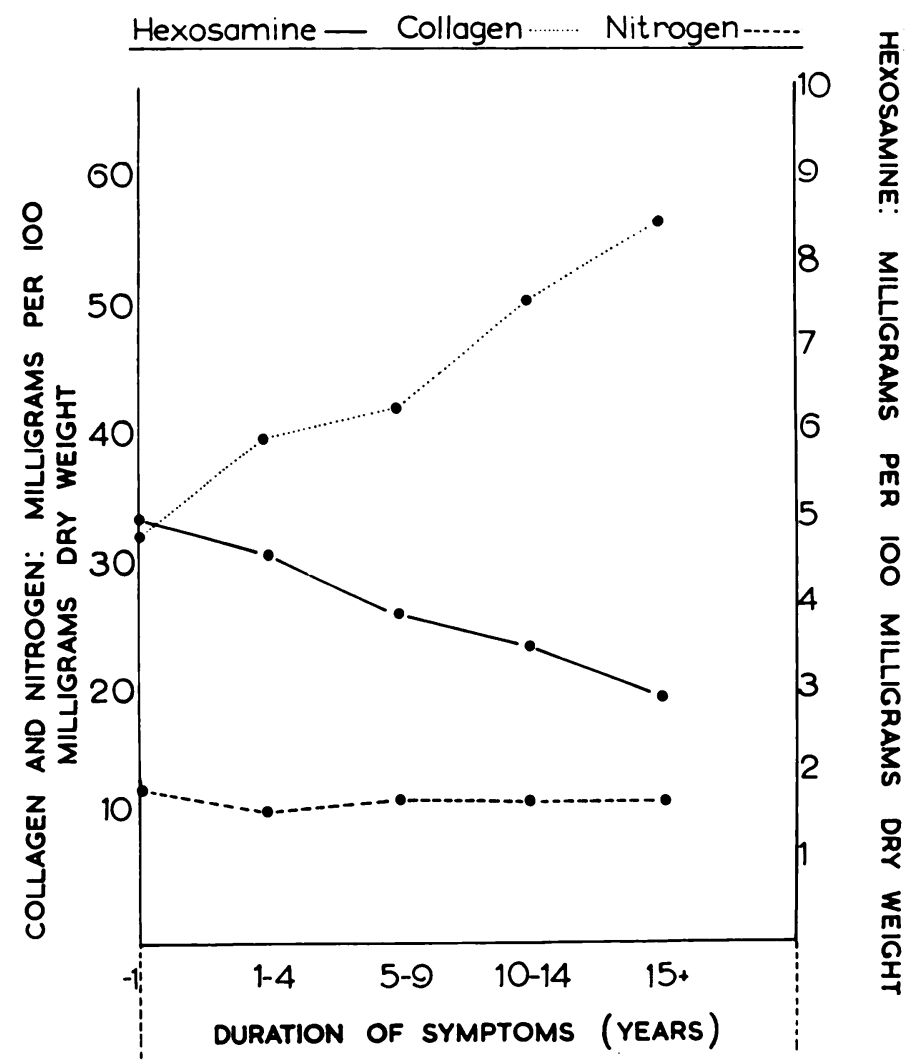

Fig. 10

The mean values for hexosamine, collagen and total protein (as nitrogen) shown in relation to the duration of symptoms. Note the increase of the collagen values and decrease of hexosamine values with increase in the duration of symptoms.

processes, it appears that separation of the protein fraction of the mucoprotein provides the material necessary for the build-up of collagen, and must therefore be presumed to precede such build-up. This would be a period-when polysaccharide had been depolymerised, but collagen had not yet taken its place-when a disc would be particularly vulnerable, and the existence of such a phase was indeed previously postulated by one of us on purely physical grounds. The vulnerability would be the greater, the greater were the initial polysaccharide content, which may again explain the susceptibility to derangement in the fourth decade.

The condition of the "healed" prolapsed disc can reliably be deduced from Figure 10 as being a state of fibrosis, not corresponding to any point in the normal ageing sequence. As a corollary of this, it must be assumed that a disc, once prolapsed, will never return to normal, and that treatment should be directed at encouraging the formation of fibrous tissue. This is presumably the basis of the success of immobilisation. The present data provide 
reinforcement for the view that treatment should be conservative, in the form of protection of the affected segment of spine, unless persisting symptoms or signs of nerve pressure indicate otherwise. Equally, with present methods, there is no justification for describing a disc derangement as "cured": this will be possible only when some means is found of restoring the polysaccharide content to normal. Hirsch (1959) has suggested that treatment may become possible in the future by the development of a " chondrolytic enzyme, that, injected into a disc, would cause a connective tissue reaction." On the basis of the present work the encouragement of such a reaction would be a logical step, but it seems likely that the use of a purely depolymerising agent would, initially at any rate, increase the hydrostatic effects from which the disc was already suffering.

The constancy of the nitrogen levels within each of the two groups has already been referred to. It is a totally unexpected finding, which casts light not only on the normal process and its derangement but also, possibly, on the mechanism of the "maturation" of collagen in general. It is to be noted that nitrogen can be derived only from two main sources in the disc-one the collagen, the other the protein moiety of the polysaccharide/protein complex. As age progresses in the normal disc, and as the disability progresses in the prolapsing one (Figs. 5 and 10), both these constituents undergo major changes, and it is little short of astonishing that, in the face of this, the sum total of protein should remain constant. The only readily available explanation is that the addition to the collagen must be derived from the protein liberated from the mucoprotein breakdown. The possibility of mucopolysaccharides participating in collagen " maturation " has recently been formulated by Jackson $(1954,1957)$ on histochemical grounds. It seems likely that detailed study of the nucleus pulposus will provide further evidence in favour of this concept: electron microscopy studies at present in progress in Aberdeen lend some support to it, and will be reported separately. Whether or not this proves to be a generally occurring mechanism throughout the body, there can be no doubt that, in the disc, the process of normal ageing involves some such transfer of protein, and that the provision of the material for the increase in collagen is in some way related to the gradual decrease in mucoprotein after the peak levels of the fourth decade have been reached. The breakdown of a protein/polysaccharide link can therefore be confidently postulated as the change underlying the physiological ageing process.

In the prolapsing disc this process is superseded by another, in which, irrespective of age, the polysaccharide falls sharply to much lower levels than are ever encountered in the physiological process; collagen meantime rises equally sharply and total protein again remains constant, but at a level about twice as high as normal. The rapidity and extent of these changes suggest that, compared with the physiological process, multiple and probably different polysaccharide/protein linkages are being broken down. Such a breakdown would certainly produce altered imbibition characteristics of the kind already shown to be typical of prolapsed discs, and it is therefore put forward now as the chemical change underlying disc derangement.

\section{SUMMARY AND CONCLUSIONS}

Two groups of intervertebral discs, one normal, as obtained from the post-mortem room, the other prolapsed, as removed at operation, have been compared by chemical analysis of their principal constituents. There is a progression of chemical changes associated with the ageing of the normal disc. This shows not only the expected slight increase in collagen as age advances, but also, surprisingly, that the polysaccharide content rises to a maximum in the fourth decade, in the same way as does polysaccharide in costal cartilage. In prolapsed discs the ageing process is superseded by a different and distinctive progression, which advances, not according to age, but according to the duration of the prolapse. There is a critical level to which the polysaccharide content must apparently fall, irrespective of the normal level for the patient's age, before a prolapse occurs. Normal ageing probably consists in the breakdown

vol. 43 B, NO. 1, FEBRUARY 1961 
of a particular polysaccharide/protein linkage, with coincident "maturation" of collagen. In the prolapsing disc multiple, and possibly different, linkages are rapidly broken down. This depolymerisation of a gel structure must be presumed to be the basis of the decreased imbibition capacity of the nucleus pulposus, and to be the source of the hydrostatic abnormalities which result in disc prolapse.

In both normal and prolapsing discs the products of mucopolysaccharide breakdown appear to participate in the metabolism of collagen.

\section{STATISTICAL APPENDIX}

The differences between the normal (necropsy) discs and the discs removed at operation shown in Table I are statistically highly significant of a real difference between the groups. It has to be noted that the variation of collagen values is significantly greater in the prolapsed than in the normal discs.

The effect of age-The analysis of hexosamine values for normal discs indicates a parabolic regression with a maximum between thirty and forty years of age. The relation is significant at the 5 per cent level and the standard error of the estimate is 2.01 milligrams per cent (for the regression equation see Figure 1). In normal discs there is a slight tendency for the reducing sugar content to increase with the patient's age but the relationship fails to reach statistical significance (Fig. 2). Collagen values in normal discs increase with the patient's age. The relation is significant at the 5 per cent level and the standard error of the estimate is 4.88 milligrams per cent. The regression equation is shown in Figure 4.

There is virtually no trend with age in nitrogen values (Fig. 3).

In contrast to the above findings there is no significant change with age in the estimates obtained for prolapsed discs (Figs. 6 to 9).

The duration of disability-The observed values for hexosamine tend to decrease and those for collagen to increase as the duration of disability increases. The correlation coefficients between duration and hexosamine and collagen respectively are -0.29 and +0.37 . These coefficients are statistically significant at 5 per cent and 1 per cent levels respectively.

Relationship between hexosamine and collagen content-While the correlation $+0 \cdot 11$ between hexosamine and collagen content in normal discs is not significant, there is a significant (at 2 per cent level) negative correlation -0.34 between the two variables in prolapsed discs, indicating that the collagen values tend to increase as hexosamine decreases. The difference between the two coefficients is significant at the 5 per cent level, suggesting that the observed difference in the joint behaviour of hexosamine and collagen is characteristic of prolapsed discs.

When the prolapsed discs are divided into two groups according to the duration of disability and the hexosamine/collagen correlations in the two groups are compared the following results are obtained. For the discs from patients with less than two years' disability the correlation between hexosamine and collagen is -0.52 . For those from patients with disability lasting two years or more the correlation is $-0 \cdot 24$. Although the two coefficients are not statistically different, the difference is rather striking, especially since the correlation in the long duration group is enhanced by five unusually high collagen values coupled with rather low hexosamine contents. This observation may have no meaning, but it might on the other hand suggest that prolonged treatment somehow reduces the initial low hexosamine/high collagen relation existing in prolapsed discs.

This work was made possible by a research grant made to one of us (N. G. C. H.) by the Board of Management of Aberdeen General Hospitals, to whom therefore we are greatly indebted. Laboratory facilities were very kindly made available by Dr A. Lyall, Head of the Department of Clinical Chemistry, Aberdeen University. and we have had much helpful advice from Dr G. P. Fraser of that department, and from Professor J. Young of the Department of Pathology. We owe particular thanks to Mrs Brenda Kay for her meticulous technical work, and to Mr J. Watt of the Department of Pathology for the provision of necropsy specimens. Colleagues in the Orthopaedic Department contributed many of the operative specimens. The figures are the work of Mr G. Adams, formerly Chief Technician in the Clinical Chemistry Department, and Mr W. Topp, clinical photographer. 


\section{REFERENCES}

Birkett, A. N. (1950): Injuries and Derangements of the Spinal Column. In Modern Trends in Orthopaedics. Edited by Sir Harry Platt. London: Butterworth \& Co. (Publishers) Ltd.

Bush, H. D., Horton, W. G., Smare, D. L., and Naylor, A. (1956): Fluid Content of the Nucleus Pulposus as a Factor in the Disk Syndrome. British Medical Journal, ii, 81.

Charnley, J. (1952): The Imbibition of Fluid as a Cause of Herniation of the Nucleus Pulposus. Lancet, i, 124.

CONSDEN, R. (1958): Personal communication.

Davidson, E. A., and Woodhall, B. (1959): Biochemical Alterations in Herniated Intervertebral Disks. Journal of Biological Chemistry, 234, 2,951.

Elson, L. A., and Morgan, W. T. J. (1933): A Colorimetric Method for the Determination of Glucosamine and Chondrosamine. Biochemical Journal, 27, 1,824.

Hall, O. D., Floyd, P. F., Happey, F., Horton, W. G., and Naylor, A. (1957): Mucopolysaccharides of Human Nuclei Pulposi. Nature, 179, 1,078.

Hass, G. M. (1943): Studies of Cartilage. IV. A Morphologic and Chemical Analysis of Aging Human Costal Cartilage. Archives of Pathology, 35, 275.

Hendry, N. G. C. (1958a): The Hydration of the Nucleus Pulposus and its Relation to Intervertebral Disc Derangement. Journal of Bone and Joint Surgery, 40-B, 132.

Hendry, N. G. C. (1958b): Physical Changes in the Prolapsed Disc. Lancet, ii, 158.

Hirsch, C. (1959): Studies on the Pathology of Low Back Pain. Journal of Bone and Joint Surgery, 41-B, 237.

JACKson, D. S. (1954): The Nature of Collagen-Chondroitin Sulphate Linkages in Tendon. Biochemical Journal, 56, 699.

JaCKsON, D. S. (1957): The Formation and Breakdown of Connective Tissue. In Connective Tissue. A Symposium. Edited by R. E. Tunbridge, M. Keech, J. F. Delafresnaye and G. C. Wood. Oxford: Blackwell Scientific Publications.

LanCet (1959): Annotation. The Protruded Disc. Lancet, i, 1,034.

Martin, C. J., and Axelrod, A. E. (1953): A Modified Method for Determination of Hydroxyproline. Proceedings of the Society for Experimental Biology and Medicine, 83, 461.

NAylor, A., Happey, F. and Macrae, T. (1954): The Collagenous Changes in the Intervertebral Disk with Age and their Effect on its Elasticity. British Medical Journal, ii, 570.

Naylor, A., and Smare, D. L. (1953): Fluid Content of the Nucleus Pulposus as a Factor in the Disk Syndrome. British Medical Journal, ii, 975.

Nelson, N. (1944): A Photometric Adaptation of the Somogyi Method for the Determination of Glucose. Journal of Biological Chemistry, 153, 375.

Neumann, R. E., and Logan, M. A. (1950a): The Determination of Collagen and Elastin in Tissues. Journal of Biological Chemistry, 186, 549.

Neumann, R. E., and Logan, M. A. (1950b): The Determination of Hydroxyproline. Journal of Biological Chemistry, 184, 299.

Smare, D. L., Happey, F., and Naylor, A. (1958): Physical Changes in the Prolapsed Disc. Lancet, ii, 157. Sylvén, B. (1951): On the Biology of the Nucleus Pulposus. Acta Orthopaedica Scandinavica, 20, 275. 